\title{
Primary mediastinal synovial sarcoma: clinical, radiologic, and pathologic features in five cases
}

\author{
Paul H Hartel ${ }^{1,2 *}$ and John E Parker ${ }^{2}$ \\ ${ }^{1}$ Consultant Histopathologist, Sligo University Hospital, Sligo, Ireland \\ ${ }^{2}$ Section of Pulmonary and Critical Care Medicine, Dept. of Medicine, West Virginia University School of Medicine, Morgantown, WV, USA
}

\begin{abstract}
Primary mediastinal synovial sarcoma is rare and poses a diagnostic challenge particularly when unusual histologic features are present and $\mathrm{t}$ (x;18) is negative. Five cases of primary mediastinal synovial sarcoma were evaluated to define clinicopathologic features including unusual histology that may result in misdiagnosis. Clinically, compared with pulmonary synovial sarcomas, mediastinal synovial sarcomas occurred in younger patients and showed male predominance. Radiology images were reviewed. Histologically, tumors showed many identical characteristics of typical pulmonary and soft tissue synovial sarcomas with dense cellularity, interlacing fascicles, hyalinized stroma, and mast cell influx with focal hemangiopericytoma-like vasculature and calcification. In contrast, they showed no myxoid change, more infiltrative growth, and focal unusual histology not usually seen with soft tissue synovial sarcoma but typical of other neoplasms. These included Verocay bodies [1], papillary structures with fibrovascular cores [1], and adenomatoid change [1]. Immunohistochemistry demonstrated expected expression of focal cytokeratins, CD99, Bcl-2, and smooth muscle actin. Three of 5 tumors were positive for $\mathrm{t}(\mathrm{x} ; 18)$, with one having no tissue remaining for testing. In conclusion, this small case series of mediastinal synovial sarcomas occurred in younger patients with male predominance compared with pulmonary synovial sarcoma, and had more infiltrative growth, less myxoid change and focal histology typical of other neoplasms. Awareness of focal unusual histology can prevent misdiagnosis particularly in $\mathrm{t}(\mathrm{x} ; 18)$ negative tumors.
\end{abstract}

\section{Introduction}

Primary mediastinal synovial sarcoma is an aggressive tumor sharing common clinical and histologic features with pulmonary and soft tissue synovial sarcoma. [1-5] Molecular testing for the pathognomonic $t$ $(\mathrm{x} ; 18)$ chromosomal translocation has enabled diagnostic confirmation in the vast majority of cases. [6] In $t(x ; 18)$ negative cases, diagnosis must rely on histologic and immunophenotypic features. The pathologic differential diagnosis of primary mediastinal synovial sarcoma is particularly challenging when histologic features unusual to synovial sarcoma, but common to other neoplasms are focally present. This challenge is compounded with negative $t(x ; 18)$ findings. We evaluated 5 cases of primary mediastinal synovial sarcoma to compare clinicopathologic findings with those reported for pulmonary and soft tissue synovial sarcoma and bring awareness of unusual histology in this entity.

\section{Materials and methods}

Five cases of known mediastinal synovial sarcoma from 1981 to 2006 were retrieved from tissue archives. Clinical data were obtained from patient records. Hematoxylin and eosin stained sections were available for each case. Tumors were subtyped as monophasic or biphasic according to World Health Organization criteria. [7] Grading by tumor cell differentiation, mitotic rate, and necrosis was performed following the French Federation of Cancer Centers (FNCLCC) scheme. Unusual histologic features were noted, and immunohistochemistry was performed on paraffin embedded sections using commercially available antibodies (Table 1). Molecular analysis was performed on RNA extracted from paraffin embedded samples. SYT/SSX RNA fusion transcripts resulting from $\mathrm{t}(\mathrm{x} ; 18)(\mathrm{p} 11 ; \mathrm{q} 11)$ translocation were detected

\begin{tabular}{|c|c|c|c|}
\hline & Clone & Titer & Source \\
\hline Pancytokeratin & $\mathrm{AE} 1 / \mathrm{AE} 3$ & $1: 200$ & $\begin{array}{l}\text { Roche, Mannheim, } \\
\text { Germany }\end{array}$ \\
\hline Cytokeratin-7 & OV TL12/30 & $1: 160$ & $\begin{array}{c}\text { Dako, Carpinteria, } \\
\text { CA }\end{array}$ \\
\hline $\begin{array}{c}\text { Epithelial } \\
\text { membrane antigen }\end{array}$ & E29 & $1: 100$ & $\begin{array}{c}\text { Dako, Carpinteria, } \\
\text { CA }\end{array}$ \\
\hline Cytokeratin 5/6 & D5/16B4 & $1: 20$ & $\begin{array}{c}\text { Dako, Carpinteria, } \\
\text { CA }\end{array}$ \\
\hline Calretinin & CAL 3F5 & $1: 50$ & $\begin{array}{l}\text { Zymed, San } \\
\text { Francisco, CA }\end{array}$ \\
\hline Bcl-2 & 124 & $1: 20$ & $\begin{array}{c}\text { Dako, Carpinteria, } \\
\text { CA }\end{array}$ \\
\hline CD56 & $123 \mathrm{C} 3$ & $1: 100$ & $\begin{array}{c}\text { Caltag, Burlingame, } \\
\text { CA }\end{array}$ \\
\hline CD99 & $12 \mathrm{E} 7$ & $1: 80$ & $\begin{array}{c}\text { Dako, Carpinteria, } \\
\text { CA }\end{array}$ \\
\hline S-100 & Polyclonal & $1: 800$ & $\begin{array}{c}\text { Dako, Carpinteria, } \\
\text { CA }\end{array}$ \\
\hline $\begin{array}{c}\text { Smooth Muscle } \\
\text { Actin }\end{array}$ & $1 \mathrm{~A} 4$ & $1: 800$ & $\begin{array}{c}\text { Sigma, St. Louis, } \\
\text { MO }\end{array}$ \\
\hline
\end{tabular}

using real-time reverse transcriptase-polymerase chain reaction. [8] Subtyping of SYT/SSX 1 and 2 fusion transcripts was performed using methods previously described. [8]

${ }^{\star}$ Correspondence to: Paul Hartel, Sligo University Hospital, Histology, Level 4, The Mall Sligo, Co. Sligo, Ireland, E-mail: phartel16@gmail.com

Key words: mediastinum, synovial sarcoma, histology, molecular translocation

Received: March 07, 2018; Accepted: April 20, 2018; Published: April 24, 2018 


\section{Results}

\section{Clinical findings}

Pertinent clinical features are presented in Table 2. The study group included 4 males and one female ranging from 10 to 71 years of age (mean, 36). The most common presenting symptoms were chest pain and shortness of breath. Surgical procedures of primary tumour included excision $(n=2)$, and open biopsy $(n=3)$. Local recurrence, metastases, and survival data were not different from pulmonary synovial sarcoma [9].

Radiology was not available in any of the mediastinal cases; however, radiologic images were available from 25 primary pulmonary synovial sarcomas which generally show virtually identical gross pathologic and histologic features [9]. To the extent that high resolution imaging is as sensitive as gross pathology including " $1 \mathrm{x}$ " histology, results are at least comparable. On chest radiographs, tumors appeared homogeneous with sharply marginated borders. There was no cavitation, calcification, or lymphadenopathy. On computed tomography, these tumors showed homogeneous or heterogeneous enhancement without evidence of bone destruction or chest wall invasion. On magnetic resonance, T1weighted and T2-weighted images showed a well-circumscribed mass without evidence of speculation or satellite nodules. T2-weighted images included nodular areas of intermediate signal intensity combined with discreet or cystic areas of high signal intensity most consistent with necrosis or hemorrhage (Figure 1).

\section{Histologic findings}

Histologic findings are presented in Table 3 and shown in Figures 2 and 3. Tumor size was not available, but tumors were described as soft, tan-gray masses with foci of necrosis. Histologically, tumors were monophasic $(n=4)$ or biphasic $(n=1)$. Tumors were grade 2 $(n=5)$ with no grade 3 (poorly differentiated) tumors according to French Federation of Cancer Centers (FNCLCC) grading. Tumor cell

Table 2 Clinical findings

\begin{tabular}{|l|c|}
\hline Mean age, years & 36 \\
\hline Gender: & \\
Male & 4 \\
Female & 1 \\
\hline Common symptoms: & 2 \\
Chest pain & 1 \\
Dyspnea & \\
\hline Surgical Procedure & \\
Excision of mass & 2 \\
Open biopsy & 3 \\
\hline
\end{tabular}

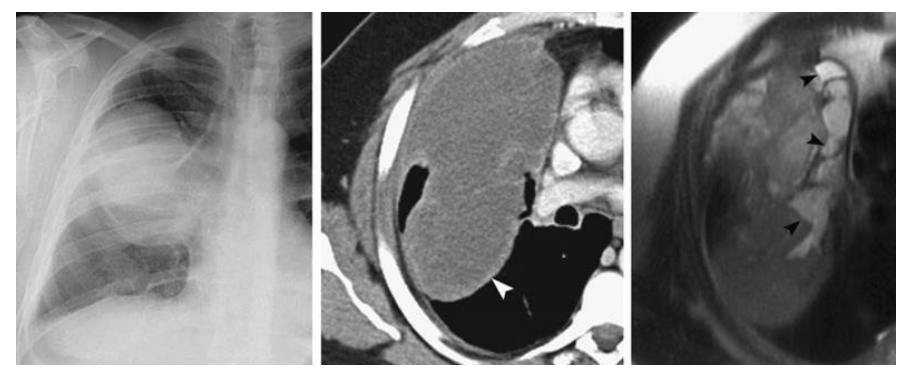

Figure 1. Chest radiograph demonstrates a mass with smooth borders. Contrast-enhanced CT scan demonstrates a large low attenuation mass with rim enhancement (arrowhead) and internal septations. Axial T2-weighted (2110/57.6) magnetic resonance image shows greater contrast among internal components, with well-demarcated spaces (arrowheads) which suggest cysts
Table 3 Histologic findings

\begin{tabular}{|l|c|}
\hline Subtypes & \\
Monophasic & 4 \\
Biphasic & 1 \\
Infiltrative growth & 3 \\
\hline Typical histology & \\
Dense interlacing fascicles & 5 \\
Eosinophilic stroma & 5 \\
Mast cell influx & 5 \\
HPC-like vasculature & 3 \\
Myxoid change & 1 \\
\hline Unusual histology (common to other & \\
neoplasms, focally present) & \\
Verocay body-like areas & 1 \\
Papillary structures & 1 \\
Adenomatoid areas & 1 \\
\hline
\end{tabular}

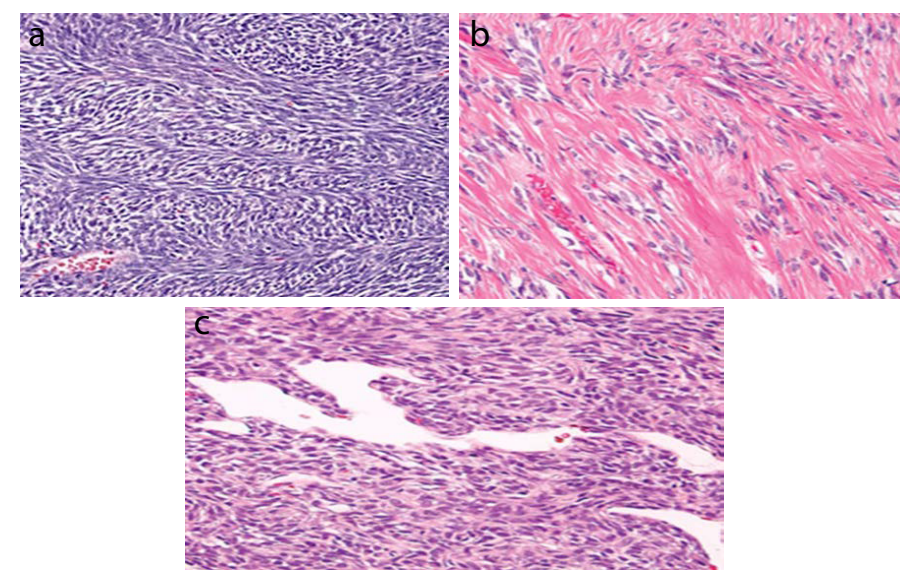

Figure 2. Typical histologic features of mediastinal synovial sarcoma, characteristically composed of (a) densely cellular interlacing fascicles, (b)eosinophilic stroma and (c) hemangiopericytoma-like vasculature.

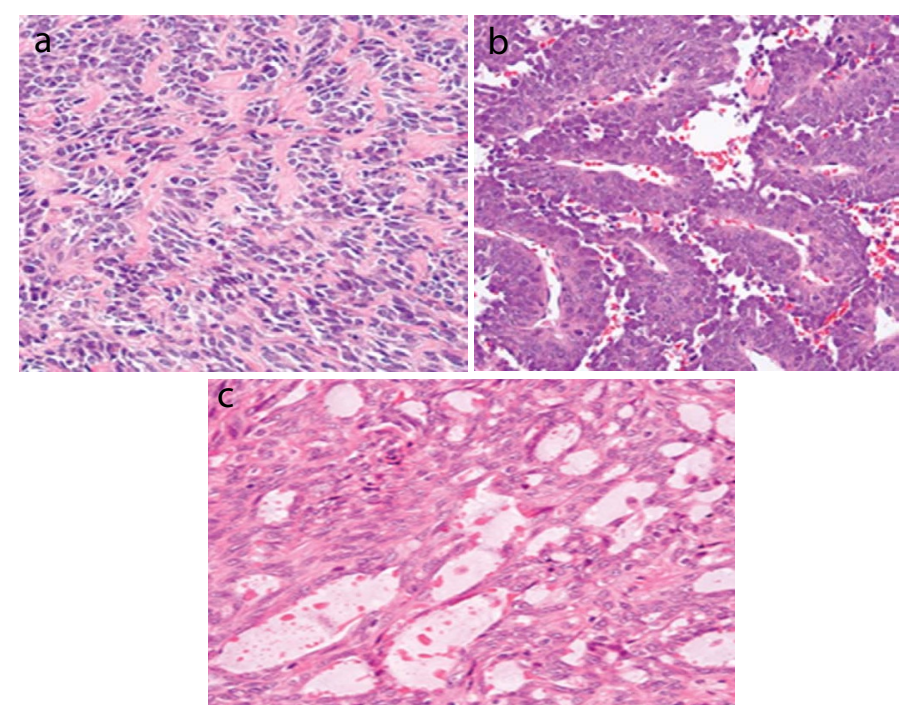

Figure 3. Unusual histology that may lead to misdiagnosis include (a) Verocay body-like areas, (b) papillary formations, and (c) adenomatoid appearance.

morphology included spindle cells $(\mathrm{n}=3)$ or a combination of spindle and round/epithelioid cells $(\mathrm{n}=2)$. Mitoses ranged from 1 to 15 per 10 high power fields (mean, 7 ). Necrosis was present in 4 tumors $(<50 \%)$.

Histologic features typical of pulmonary and soft tissue synovial sarcoma were seen and included dense cellularity $(n=5)$, interlacing fascicles $(n=5)$, and hyalinized or eosinophilic stroma $(n=5)$. Mast 
cell influx $(n=5)$, hemangiopericytoma-like vasculature $(n=3)$, focal myxoid change $(n=1)$ were also seen (Figure 2$)$. Unusual histologic features were focal, noted in at least 1 but no more than 4 slides per case, varying from 4 to 90 high power fields and included Verocay body-like areas $(n=1)$, well-formed papillary structures $(n=1)$, and adenomatoid areas $(n=1)$ (Figure 3$)$.

\section{Immunohistochemical and molecular findings}

Immunohistochemical findings are presented in Table 4 and molecular findings in Table 5. Immunohistochemical studies showed focal positive membranous or cytoplasmic staining for epithelial markers including pancytokeratin $(n=5)$, cytokeratin $7(n=3)$, epithelial membrane antigen $(n=1)$, and cytokeratin $5 / 6(n=1)$. No tumors showed immunoreactivity for more than two cytokeratin markers. Diffuse immunoreactivity was seen with CD99 in three cases and Bcl-2 in two cases. Focal immunoreactivity was present with CD56 $(n=2)$ and smooth muscle actin $(\mathrm{n}=2)$.

The chromosomal translocation $\mathrm{t}(\mathrm{x} ; 18)$ was present in three cases studied in which two were fusion type SYT/SSX2 and one fusion type $S Y T / S S X 1$. One case was reported as $\mathrm{t}(\mathrm{x} ; 18)$ positive without information on the SSX fusion type.

\section{Discussion}

Synovial sarcoma, although rare, is a primary mediastinal neoplasm sharing distinctive clinical and pathologic features with synovial sarcomas of lung and soft tissue. The presence of focal unusual histology characteristic of more common epithelial and mesenchymal tumors may lead to misdiagnosis. This is particularly problematic in small biopsies or in primary mediastinal synovial sarcomas that are negative for the pathognomonic $\mathrm{t}(\mathrm{x} ; 18)$ translocation. We present five primary mediastinal synovial sarcoma cases for clinicopathologic characterization and comparison with pulmonary and soft tissue synovial sarcomas, including focal unusual histologic features.

Clinically, compared with pulmonary synovial sarcomas, this small series of mediastinal synovial sarcomas occurred in younger patients and showed male predominance. Histologically, tumors showed many identical characteristics of typical pulmonary and soft tissue synovial sarcomas with dense cellularity, interlacing fascicles, hyalinized stroma, and mast cell influx with focal hemangiopericytoma-like vasculature and calcification. In contrast, they showed less myxoid change, more

Table 4 Immunohistochemical findings

\begin{tabular}{|c|l|}
\hline Pancytokeratin & 5 \\
\hline Epithelial Membrane Antigen & 1 \\
\hline Cytokeratin -7 & 3 \\
\hline Calretinin & 0 \\
\hline Cytokeratin 5/6 & 2 \\
\hline CD99 & 3 \\
\hline Bcl-2 & 2 \\
\hline CD56 & 2 \\
\hline S-100 & 0 \\
\hline Smooth Muscle Actin & 2 \\
\hline
\end{tabular}

Table 5 Molecular findings

\begin{tabular}{|c|c|}
\hline Total $\mathbf{t}(\mathbf{x} ; \mathbf{1 8})$ positive & 4 \\
Total SYT/SSX1 & 1 \\
Total SYT/SSX2 & 2 \\
Total t(x;18) positive, SSX unknown & 1 \\
Total t $(\mathbf{x} ; \mathbf{1 8})$ negative & 1 \\
\hline
\end{tabular}

infiltrative growth, and focal unusual histology not usually seen with soft tissue synovial sarcoma but typical of other neoplasms. The focal unusual histology in primary mediastinal synovial sarcoma can erroneously suggest more common primary and metastatic pulmonary neoplasms. Verocay body-like areas can occur which are similar to those seen in malignant peripheral nerve sheath tumor.[10] The stromal background of malignant peripheral nerve sheath tumor, however, typically lacks hyalinization and appears more basophilic. Primary mediastinal synovial sarcoma is often immunoreactive for cytokeratin 7 , a finding not generally seen in malignant peripheral nerve sheath tumor, $[11,12]$ and negative with S-100. Clinically, malignant peripheral nerve sheath tumors arise from nerve or neurofibroma and are associated with neurofibromatosis type I in approximately twothirds of cases. [13]

Focal well-formed papillary or adenomatoid areas in primary mediastinal synovial sarcoma may be misinterpreted as carcinoma or malignant mesothelioma. In particular, pleomorphic carcinoma can present with spindle cell and adenocarcinoma components. Carcinomas are more cytologically atypical with greater pleomorphism than primary mediastinal synovial sarcoma. Carcinomas may have areas of squamous differentiation or contain tumor giant cells, features not observed in primary mediastinal synovial sarcoma. While cytokeratins are focally expressed in primary mediastinal synovial sarcoma, diffuse positivity for epithelial markers is not characteristic. However, it should be kept in mind that spindle cell carcinomas may also be only focally positive for cytokeratins. Carcinomas share an infiltrative growth pattern with this series of mediastinal synovial sarcomas, but in contrast show regional lymph node involvement, and/or widespread metastases. While mediastinal synovial sarcomas may express CK5/6, calretinin was negative in our cases.

We present five primary mediastinal synovial sarcoma cases occurring in younger patients with male predominance compared with pulmonary synovial sarcoma, and more infiltrative growth, less myxoid change and focal unusual histologic features that may erroneously suggest more common primary and metastatic pulmonary, mediastinal, or other primary-site neoplasms. This unusual histology may be particularly challenging in small biopsies or when $t(x ; 18)$ is negative. Awareness of typical histology of mediastinal synovial sarcoma, their potential misleading unusual morphologic features, and prudent use of immunohistochemistry will prevent misdiagnosis, even in $t(x ; 18)$ negative cases.

\section{Disclosure/conflict of interest}

None of the authors have any disclosures or conflicts of interest.

\section{References}

1. Zeren H, Moran CA, Suster S, Fishback NF, Koss MN (1995) Primary pulmonary sarcomas with features of monophasic synovial sarcoma: a clinicopathological, immunohistochemical, and ultrastructural study of 25 cases. Hum Pathol 26: 474-480. [Crossref]

2. Bégueret H, Galateau-Salle F, Guillou L, Chetaille B, Brambilla E, et al. (2005) Primary intrathoracic synovial sarcoma: a clinicopathologic study of $40 \mathrm{t}(\mathrm{x} ; 18)$-positive cases from the French Sarcoma Group and the Mesopath Group. Am J Surg Pathol 29: 339346. [Crossref]

3. Essary LR, Vargas SO, Fletcher CD (2002) Primary pleuropulmonary synovial sarcoma: reappraisal of a recently described anatomic subset. Cancer 94: 459-469. [Crossref]

4. Okamoto S, Hisaoka M, Daa T, Hatakeyama K, Iwamasa T, et al. (2004) Primary pulmonary synovial sarcoma: a clinicopathologic, immunohistochemical, and molecular study of 11 cases. Hum Pathol 35: 850-856. [Crossref]

5. Suster S, Moran CA (2005) Primary synovial sarcomas of the mediastinum: a clinicopathologic, immunohistochemical, and ultrastructural study of 15 cases. Am J Surg Pathol 29: 569-578. [Crossref] 
6. Fletcher CD, Unni KK, Mertens FE, World Health Organization Classification of Tumors (2002) Pathology and Genetics of Tumors of Soft Tissue and Bone. IARC Press: Lyon, France: 427. [Crossref]

7. Travis WD, Brambilla E, Muller-Hermelink HK, Harris CC (2004) World Health Organization Classification of tumors of the Lung, Pleura, Thymus, and Heart. IARC Press: Lyon, France: 344. [Crossref]

8. Bijwaard KE, Fetsch JF, Przygodzki R, Taubenberger JK, Lichy JH (2002) Detection of SYT-SSX fusion transcripts in archival synovial sarcomas by real-time reverse transcriptase-polymerase chain reaction. J Mol Diagn 4: 59-64. [Crossref]

9. Smith JC, Frazier AA, Galvin JR, Lichy JH, et al. (2007) Primary pulmonary and mediastinal synovial sarcoma: a clinicopathologic study of 60 cases and comparison with five prior series. Mod Pathol 20: 760-769. [Crossref]
10. Miettinen ME (2003) Diagnostic Soft Tissue Pathology. Churchill Livingstone, New York: 463-468.

11. Smith TA, Machen SK, Fisher C, Goldblum JR (1999) Usefulness of cytokeratin subsets for distinguishing monophasic synovial sarcoma from malignant peripheral nerve sheath tumor. Am J Clin Pathol 112: 641-648. [Crossref]

12. Machen SK, Fisher C, Gautam RS, Tubbs RR, Goldblum JR (1998) Utility of cytokeratin subsets for distinguishing poorly differentiated synovial sarcoma from peripheral primitive neuroectodermal tumour. Histopathology 33: 501-507. [Crossref]

13. Kleihues P, Cavenee WKE, World Health Organization Classification of Tumors (2000) Pathology and Genetics of Tumors of the Central Nervous System: 172-174.

Copyright: $\odot 2018$ Hartel PH. This is an open-access article distributed under the terms of the Creative Commons Attribution License, which permits unrestricted use, distribution, and reproduction in any medium, provided the original author and source are credited. 